\title{
Multi-Terminal VSC-HVDC for Wind Power in Thailand
}

\author{
Narin Watanakul \\ Department of Electrical and Computer Engineering, Faculty of Engineering, Thammasat University, Thailand
}

Copyright $(\mathrm{C} 2017$ by authors, all rights reserved. Authors agree that this article remains permanently open access under the terms of the Creative Commons Attribution License 4.0 International License

\begin{abstract}
This paper presents an application of an asynchronous back to back VSC-HVDC system, which uses multilevel converter, which uses two-level series voltage connection SPWM converter topology technique. The control strategy is design and implementation of Multi-Terminal on a VSC-HVDC network, representing the future transnational network in Thailand with rated 300MVA $( \pm 300 \mathrm{kV})$. The capability to dispatch the offshore wind power as well as the traded power among the onshore grids is explored under wind speed changes. The controller of an asynchronous back to back VSC-HVDC system, the process $\mathrm{PQ}$ controller can realize the designated control of active power $(\mathrm{P})$ and reactive power $(\mathrm{Q})$ strategy. The $\mathrm{PQ}$ power can exchange controlled independently, the experimental in laboratory tests, and simulation results got from MATLAB/Simulink program software, The Simulation results, the PQ-controller results consist of PMSG rotational speed, voltages and currents, the active and reactive power, DC-bus (kVDC), DC-power (Pdc) and step response command active power, the control of DC-bus voltage is assured by regulation of the active and reactive power. The control strategy of PQ-control to the two-level SPWM converters topology technique for the realization of HVDC system, and to confirm the control strategy provides satisfactory response and strong stability. The system of wind power application is used as a guideline for analyzing and design of the data process control with the PQ-control HVDC system.
\end{abstract}

Keywords High Voltage Direct Current (HVDC), Multi-Terminal VSC-HVDC, Voltage Source Converter (VSC), PQ-control, Offshore Wind Farms

\section{Background / Objectives}

Wind power generation has been in rapid growth, but they have characteristics of randomness, intermittent, uncontrollable. Although the idea of effective renewable energy use as a means of coping with environmental and resource problems, especially of reducing $\mathrm{CO}_{2}$ emissions, is globally attractive, inappropriate application of distributed renewable power generation systems can be a cause of insecure power supply. That is, the widespread use of various kinds of distributed renewable power sources which would impact the quality of the power supply within a micro-grid power system, causing many control problems. Electrical energy is normally transmitted by means of transmission line. An electric circuit is an interconnection of electrical elements connected together in a closed path so that an electric current may flow continuously. Transmission by ac replaced dc transmission because of the case and efficiency with which voltage can be transformed using transformers. The disadvantage of AC transmit ion system, the volume of copper used is much more than the D.C. system, the inductance and capacitance of the line effects the regulation of the line which is increased due to skin effect the line resistance is increased which further increases the skin effect, the AC transmission lines are more effective to corona than D.C. lines, in an A.C. system the speed of the generator and alternators is not economical, variation of these speeds must be controlled within very low limits, in cable the alternating current cause sheath loss. The construction of the transmission lines is not as easy as in case of D.C. lines, the alternator must be synchronized, before they are made to run in parallel. The factor of limitation of AC transmit ion system for long-distance transmit ion consist of voltage stability, reactive power problems, steady-state stability and transient stability. For interconnected of AC transmit ion system consist of load-flow problems (management of congestion), frequency control, voltage stability, inter-area oscillation and blackout risk due to cascading effects. For example HVDC of Thailand and Malaysia installed in June 2002. The HVDC Thailand-Malaysia is a 110 kilometers long HVDC power line between Khlong Ngae in Thailand at $6^{\circ} 42^{\prime} 56^{\prime \prime} \mathrm{N}$ $100^{\circ} 27^{\prime} 08^{\prime \prime} \mathrm{E}$, which crosses the border between Malaysia and Thailand at $6^{\circ} 31^{\prime} 47^{\prime \prime} \mathrm{N} 100^{\circ} 24^{\prime} 11^{\prime \prime} \mathrm{E}$, serves for the coupling of the asynchronously operated power grids. The HVDC connection Thailand-Malaysia is a monopole $300 \mathrm{kV}$ DC overhead line with a maximum transmission rate of 300 megawatts (MW) as shows in Figure1. 


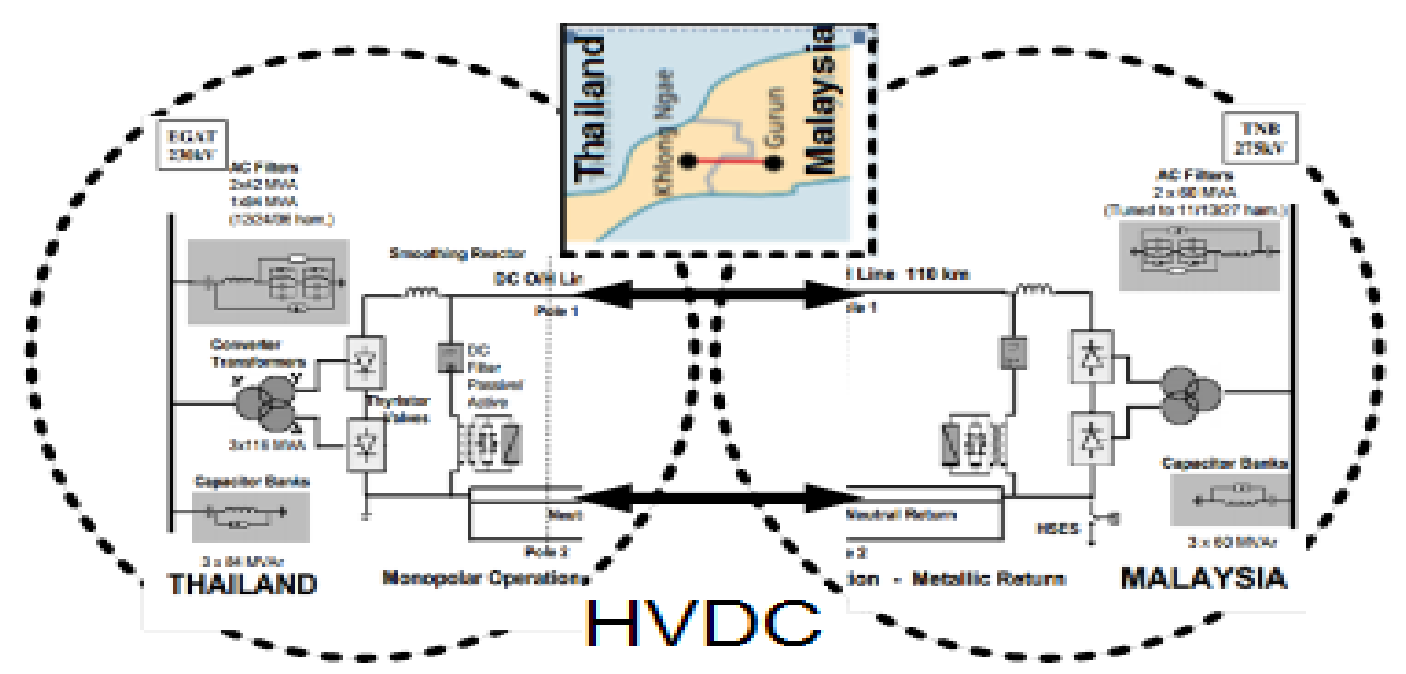

Figure 1. Map on location of this HVDC long-distance transmission system between interconnecting the $230 \mathrm{kV}$ AC network of Thailand with the $275 \mathrm{kV}$ $\mathrm{AC}$ network of Malaysia and typical schematic of distribution power system with HVDC converter station main equipment

For economic and environmental protection reasons there has been a tendency towards replacing the gas turbines with electric supply from onshore grid, in the study of ABB Power Technologies.[1]. An interconnection between the offshore wind farms, the oil and gas platforms and onshore grid can result in reduced operational costs, increased reliability and reduced $\mathrm{CO}_{2}$ emissions. A Multi-Terminal HVDC (MTDC) network will then be the core of such an interconnection system. MTDC can also open new power market opportunities and result in better utilization of transmission lines, in the study, J.G. Slootweg.[2]. For such a Multi-Terminal offshore network, where large power would be transmitted over long distance, application of high-voltage alternating-current transmission (HVAC) technology may be difficult to implement due to large amount of reactive power compensation required. Thus, an alternative is to use high-voltage direct-current transmission (HVDC) technology. Moreover, since the offshore network may act as a power pool where power may be injected to and extracted from the network at different nodes, flexibility to control direction of power whilst maintaining voltage in the network is required. For such a situation, implementation of voltage sourced converter HVDC (VSC-HVDC) technology is favorable, in the study, Z. Lubosny[3] and Lars Weimers [4].

In Thailand present of installed monopole link HVDC system configurations and components in Thailand consist of $\mathrm{AC}$ switchgear, and the interconnecting $300 \mathrm{kV}$ DC overhead line was included in Siemens' scope of supply. Commercial operation started in 2001. Technical Data Customer Electricity Generating Authority of Thailand (EGAT) Tenaga Nasional Berhad (TNB) Project name Thailand-Malaysia Location Khlong Ngae-Gurun Power rating $300 \mathrm{MW}$, monopole Type of plant Long-distance transmission, $110 \mathrm{~km}$ Voltage levels $300 \mathrm{kVDC}, \mathrm{EGAT}: 230$ $\mathrm{kV}, 50 \mathrm{~Hz}$ TNB: $275 \mathrm{kV}, 50 \mathrm{~Hz}$ Type of thyristor Electrically-triggered-thyristor, $8 \mathrm{kV}(100 \mathrm{~mm} \varnothing)$, in the study, Luxembourg, Belgium[5]. As show in Figure 2 (a)-(b). Environmental constraints will play an important role in the power system developments, in the study, DENA Study Part 1.[6]. However, regarding the system security, have to be integrated into the system, particularly when the connecting AC links are weak and when sufficient reserve capacity in the neighboring systems is not available, in the study, M.Luther.[7]. In the future, an increasing part of the installed capacity will be connected to the distribution levels (dispersed generation), which poses additional challenges to the planning and safe operation of the systems. Power electronics will be required to control load flow, to reduce transmission losses and to avoid congestion, loop flows and voltage problems, in the study, N.G. Hingorani[8]. Basically, there are three kinds of multilevel inverters. The multilevel converter topology for the VSC transmit ion system consist of the cascade converters (CC),flying capacitor converter (FC)and neutral point clamped SPWM converter (NPC), in the study, Mohamed Flitti et al.[9] and A. Nabae et al.[10].The comparison between VSC HVDC transmission and LCC transmission. The LCC that the reverse voltage is available only for a $180^{\circ}$ interval from the firing angle $\alpha=0^{\circ}$ point of the conducting thyristor. Due to the inductance in series with the ac voltage, this process takes a certain amount of time - corresponding to the overlap angle. If the firing of this next valve is delayed too much, the commutation (transfer of current from outgoing valve to incoming valve) is not successful and this phenomenon is referred to as commutation failure. Dependence on an AC voltage source, Reactive power consumption or generation requirement for ac system. For LCC HVDC consumes reactive power of 50\% to $60 \%$ of the active power. Switchable shunt capacitor banks are necessary for reactive power compensation. For VSC HVDC transmission, the dc side voltage in a VSC is essentially kept constant. A VSC system instead can keep the same voltage polarity for power reversal. The same voltage polarity during power reversal makes the dc grid possible. 
For reactive power can be generated or absorbed. Reactive power can be controlled independently from active power control at both ends of the VSC Transmission scheme. In Figure 2 Shows Diagram of power converting wind power to electrical power in a wind turbine with PMSG. The wind turbine rotor is designed to extract maximum power from the wind and this value can be calculated as:

$$
P_{T}=\frac{1}{2} \rho A C_{p}(\beta, \lambda) v_{\omega}^{3}
$$

Where, represents $P_{T}$ :Mechanical turbine power $(W)$, $A$ represents the Blade swept area $\left(m^{2}\right), v_{\omega}$ represents the wind speed are between 4.0-5.0 $(\mathrm{m} / \mathrm{s})$ and taking for simulation $4.9(\mathrm{~m} / \mathrm{s})$, and The power coefficient $C_{p}$ can have a maximum value of 0.593 , but in reality, the aerodynamics of the rotor are not perfect and $\rho$ Air density taking $1.16\left(\mathrm{~kg} / \mathrm{m}^{3}\right)$, thus assuming Power coefficient about $C_{p}=0.47$, when $\beta=0^{\circ}$ Pitch angle (deg), $\lambda$ Tip-speed ratio is kept constant. The cut-out wind speed value (here considered $25 \mathrm{~m} / \mathrm{s}$ ).

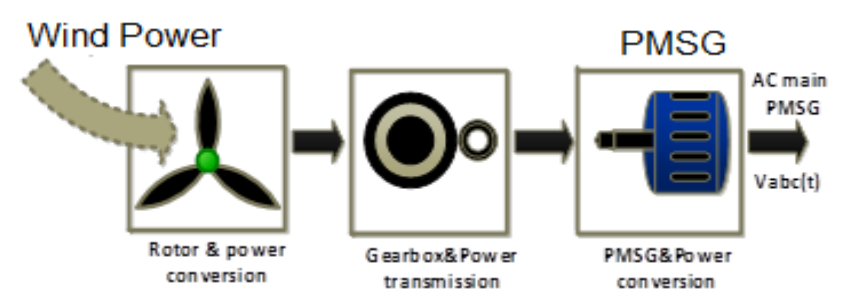

Figure 2. Diagram of wind power to electrical power in a wind turbine with PMSG

The model of the PMSG was developed in the dq synchronous reference frame, where the q-axis is 90 degrees phase shifted ahead of the d-axis with respect to the direction of rotation. In order to simplify the system, the generator was assumed to be a PMSG with surface-mounted magnets. Thus, the model of the PMSG in the dq synchronous reference frame is given by the voltage equations (2) and (3), the torque equation (4) and the mechanical equation (5).

$$
\begin{gathered}
U_{s d}=R_{s} i_{s d}+L_{d} \frac{d i_{s d}}{d t}-\omega_{r} L_{q} i_{s d} \\
U_{s q}=R_{s} i_{s q}+L_{q} \frac{d i_{s d}}{d t}+\omega_{r} \psi_{m}+\omega_{r} L_{d} i_{s d} \\
T_{e}=\frac{3}{2}\left(N_{p} \psi_{m} i_{s q}\right) \\
T_{e}-T_{L}-B \omega_{m}=J_{m} \frac{d \omega_{m}}{d t}
\end{gathered}
$$

Where $U_{s d}, U_{s q}$ represent the direct and quadrature components of the stator voltages, $i_{s d}, i_{s q}$ represent the direct and quadrature components of the stator currents, $L_{d}, L_{q}$ represent the direct and quadrature components of the stator inductances $R_{s}$ represents the stator resistance, $\omega_{m}$ represents the mechanical speed of the rotor, $\omega_{r}$ represents the electrical speed of the rotor, $\psi_{m}$ represents the permanent magnet flux linkage, $T_{e}$ represents the electromagnetically torque, $N_{p}$ represents the number of the pole-pairs.

\section{Methods}

Voltage Source Converter with uses a two-level series connection Based Multi-Terminal VSC-HVDC System. We apply Kirchhoff's voltage Law (KVL) is deduction of the power static equations with power delivered to the stiff grid. Expressing complex power $\mathrm{Eq}(6)-\mathrm{Eq}(9)$, and as shown single line diagram of equivalent circuit of power flow as shown in figure 3 .

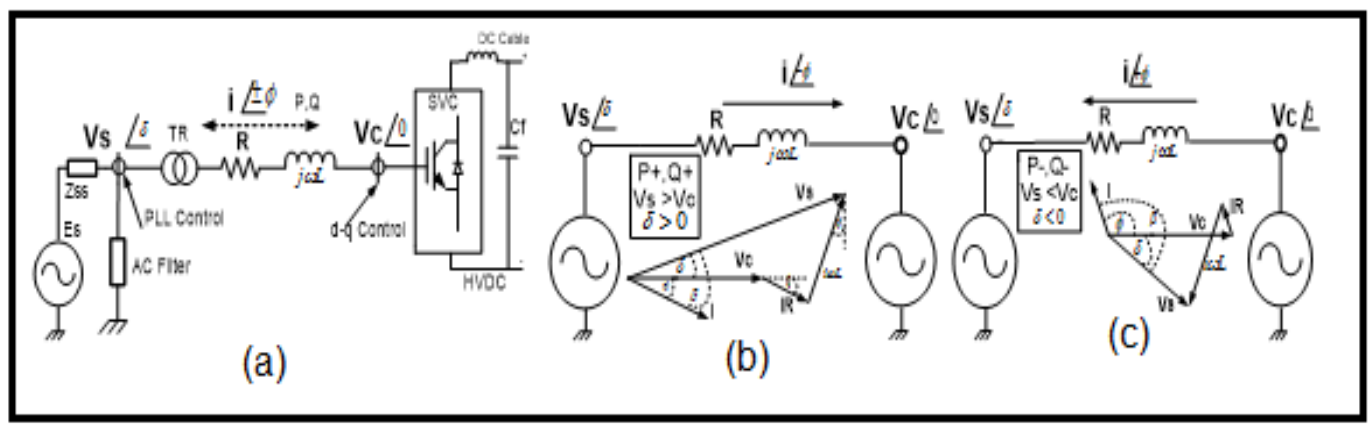

(a) Configuration

(b) Power flows $(\mathrm{P}+, \mathrm{Q}+)$

(c) Power flows (P-,Q-)

Figure 3. Phases diagram and the single line diagram of equivalent circuit of inductance (WL) and resistance (R), the total impedance coming from transformer and phase reactor, point (Vs) is the PCC of the grid ac system, Point (Vc) is the voltage source converter (VSC), (a) A typical configuration of a VSC converter terminal (b) active and reactive power flows ( $\mathrm{P}+$ and $\mathrm{Q}^{+}$) and (c) active and reactive power flow (P- and $\mathrm{Q}-$ ). 
As schematically shown in Figure 3., shows the circuit diagram configuration of a proposed Multi-Terminal VSC-HVDC system, for offshore Wind farm, voltage source converter (VSC) interconnection between from Thailand station (1) to Malaysia (2) station with control of an asynchronous back to back VSC-HVDC system, each station (1) and (2) rated 300MW (+/-300kV DC), which uses two-level SPWM converter topology. The rectifier and the inverter are interconnected through a $110 \mathrm{~km}$ cable (i.e. 2 pi section) and DC filter connected smoothing reactor (L) and capacitor $(\mathrm{C} 1=\mathrm{C} 2)$. The two terminals are interconnected by a DC link. Each station consist of phase-shift transformer winding, transformer with two separated winding (delta and wye) one wye primary winding and two secondary winding $(\Delta / Y)$, similar to a 12-pulse rectifier system, cancellation of the $5^{\text {th }}$ and $7^{\text {th }}$ can be achieved on the primary side of the transformer to the degree that these currents are balanced in each of the transformer secondary windings. The variable speed wind turbine with full scale frequency converter is an attractive solution for research on distributed power generation system. The simulation velocity of rotational speed give it is value of the velocity rotational for simulation speed, in the study, D.I.Stroe. [11], M.Ying.[12], Abdul Hamid Bhat.[13], Samah Hammadi.[14], K. Ghdemsi [15], L.M. Fernandez.[16] and Shuhui Li.[17].

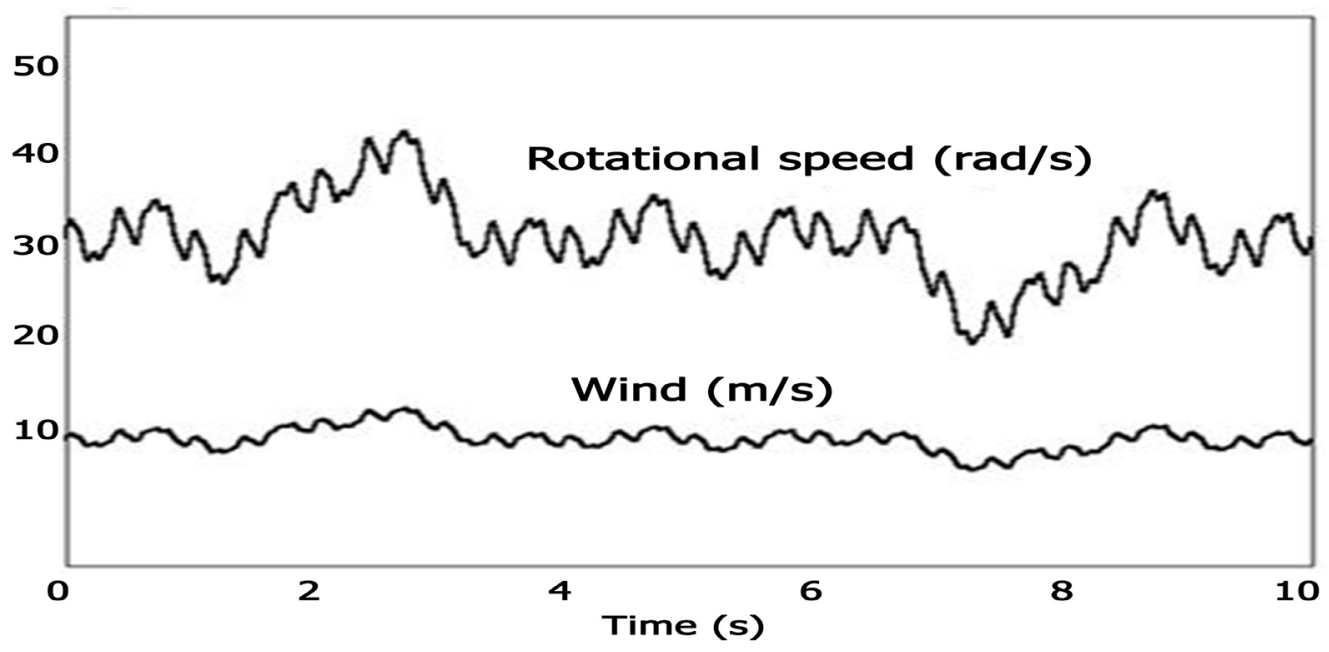

(a) Rotational speed (a) illustrates rotational speed and velocity of wind $(\mathrm{m} / \mathrm{s})$

$v(t)=10+\sin (x)-0.87 \sin (3 x)+0.75 \sin (5 x)+0.625 \sin (10 x)+0.5 \sin (30 x)+0.25 \sin (50 x)+0.125 \sin (100 x),(x=2 p i / 10)$

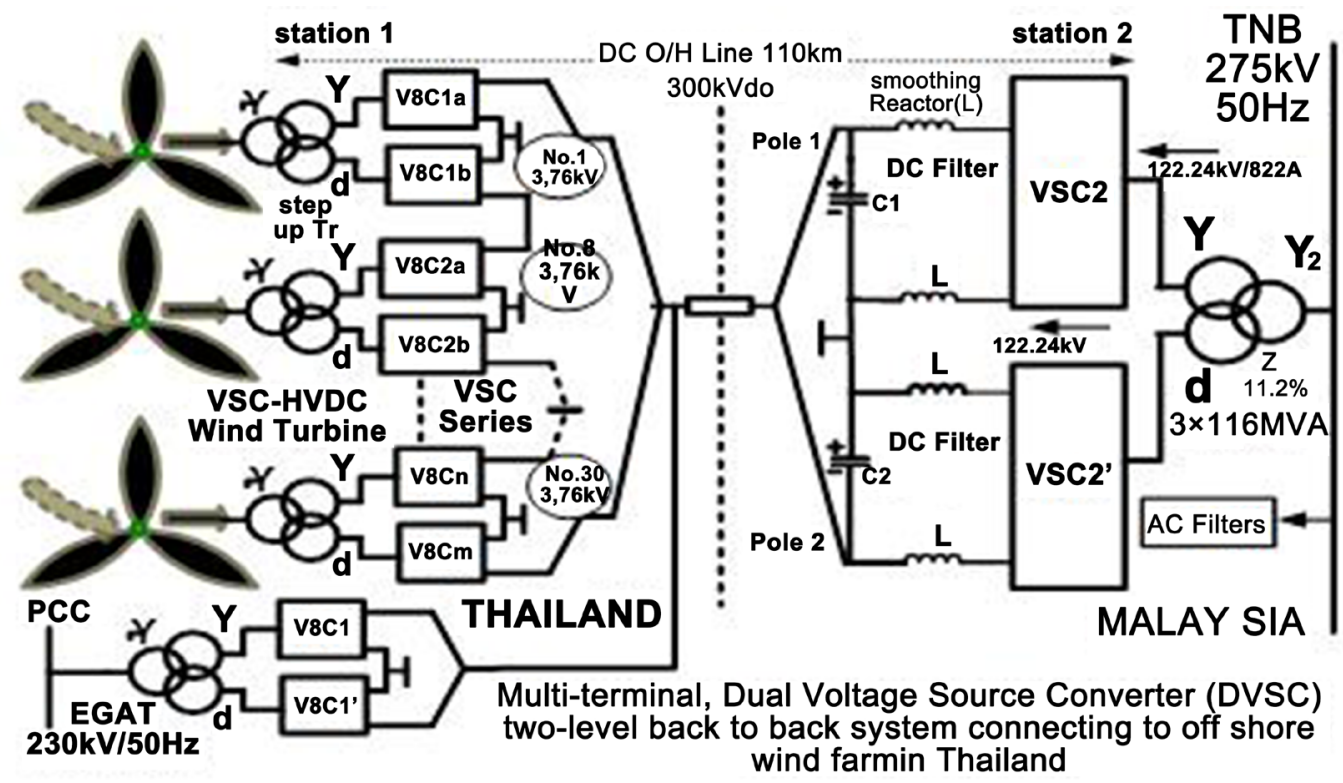

(b) Offshore and Onshore

Figure 4. Illustrates wind turbine No.1 - No.8 VDC is the series connection of HVDC type, and to Multi-Terminal VSC-HVDC system, for offshore wind farm Based HVDC Transmission system configuration. 


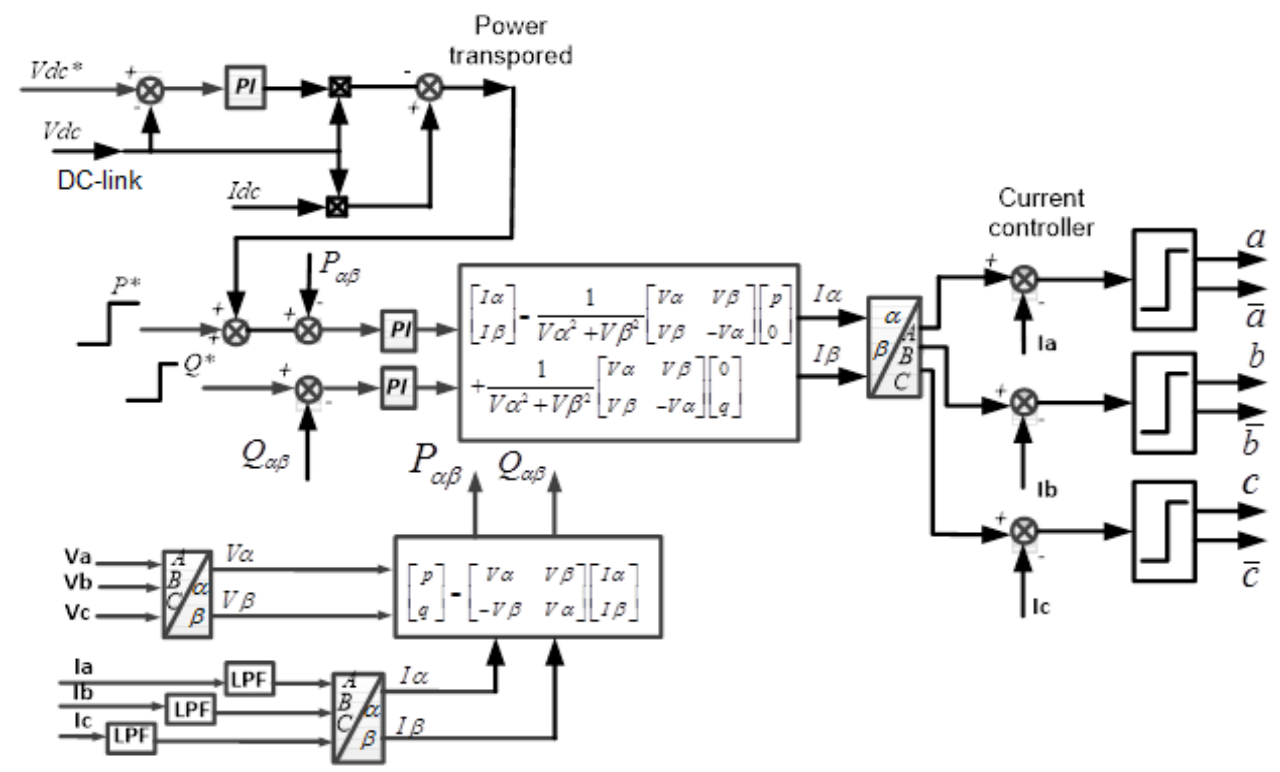

(a) Modeling Controller VSC (2-level) for Wind turbine

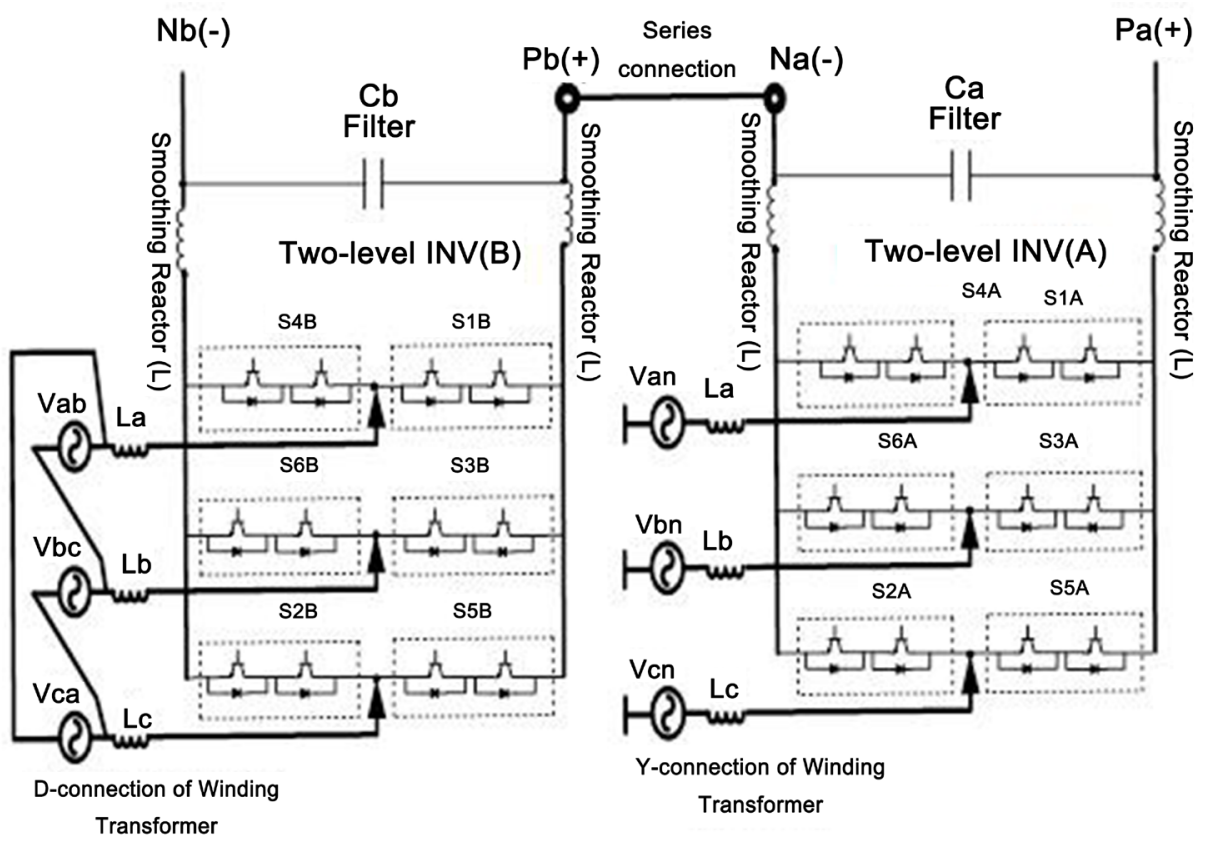

(b) Main Power Circuit Diagram

Figure 5. The part of Wind turbine, (a) modeling controller VSC and (b) main power circuit diagram of voltage source converter (VSC) with two-level series connection.

$$
\begin{aligned}
& {\left[\begin{array}{l}
p \\
q
\end{array}\right]=\left[\begin{array}{cc}
V \alpha & V \beta \\
-V \beta & V \alpha
\end{array}\right]\left[\begin{array}{c}
I \alpha \\
I \beta
\end{array}\right], \quad\left[\begin{array}{c}
i \alpha \\
i \beta
\end{array}\right]=\frac{1}{V \alpha^{2}+V \beta^{2}}\left[\begin{array}{cc}
V \alpha & V \beta \\
V \beta & -V \alpha
\end{array}\right]\left[\begin{array}{l}
p \\
q
\end{array}\right]} \\
& {\left[\begin{array}{c}
I \alpha \\
I \beta
\end{array}\right]=\frac{1}{V \alpha^{2}+V \beta^{2}}\left[\begin{array}{cc}
V \alpha & V \beta \\
V \beta & -V \alpha
\end{array}\right]\left[\begin{array}{l}
p \\
0
\end{array}\right]+\frac{1}{V \alpha^{2}+V \beta^{2}}\left[\begin{array}{cc}
V \alpha & V \beta \\
V \beta & -V \alpha
\end{array}\right]\left[\begin{array}{l}
0 \\
q
\end{array}\right]} \\
& {\left[\begin{array}{c}
I \alpha(t) \\
I \beta(t)
\end{array}\right]=\sqrt{\frac{2}{3}}\left[\begin{array}{ccc}
1 & \cos \frac{2 \pi}{3} & \cos \frac{4 \pi}{3} \\
0 & \sin \frac{2 \pi}{3} & \sin \frac{4 \pi}{3}
\end{array}\right]\left[\begin{array}{l}
I a(t) \\
I b(t) \\
I c(t)
\end{array}\right] \quad\left[\begin{array}{l}
V \alpha(t) \\
V \beta(t)
\end{array}\right]=\sqrt{\frac{2}{3}}\left[\begin{array}{ccc}
1 & \cos \frac{2 \pi}{3} & \cos \frac{4 \pi}{3} \\
0 & \sin \frac{2 \pi}{3} & \sin \frac{4 \pi}{3}
\end{array}\right]\left[\begin{array}{l}
V a(t) \\
V b(t) \\
V c(t)
\end{array}\right]} \\
& \mathrm{P}=\frac{V s \cdot V c(R \cos \delta+\omega L \sin \delta)-V c^{2} R}{R^{2}+\omega L^{2}}, \mathrm{Q}=\frac{V s \cdot V c(\omega L \cos \delta-R \sin \delta)-V c^{2} R}{R^{2}+\omega L^{2}}
\end{aligned}
$$


Figure 5 shows modeling controller of VSC and main power circuit diagram of voltage source converter (VSC). The control of the VSC based HVDC transmission system has been proposed using by Direct Power Control (PQ) controlled multilevel voltage source converter with two-level SPWM. The modelling block diagram consists of PLL (phase Lock Loop) used control with the line voltages and also to compute the transformation angle used in the $d$ and $q$-axis, using by the sine-cosine-ROM is vital for in-phase strategy controller wave form. We obtain current (Ia,Ib,Ic) and voltage $(\mathrm{Va}, \mathrm{Vb}, \mathrm{Vc})$ it is that flow pass LPF is $1^{\text {st }}$-order low-pass filter that LPF (low- Pass Filter), frequency signals setting of design Cut-off frequency $\left(f_{c}=1000 \mathrm{~Hz}\right)$. This paper describes the operation and control of the VSC based HVDC transmission system has been proposed using by equation (Eq.6 to Eq.9.) gives that reactive power (Q) and active power $(\mathrm{P})$ is proportional to the $\mathrm{DC}$ current and $\mathrm{DC}$ voltage command power transported such as (Vdc, Idc), is the power delivered to the DC bus. The controller obtain voltage and current $(V \alpha, V \beta, I \alpha, I \beta)$ in the stationary reference frame $(\alpha$, $\beta)$.Therefore, in order to improve the performances of the input PQ controller command tuning of PI controllers in such systems, cross-coupling terms $(I \alpha, I \beta)$ Controller). The VSC for wind turbine with switching frequency by using current controller SPWM.
Table 1. The proposed system consists of PMSG system whose maximum power is nominal power of each wind equal to $50 \mathrm{kVA}$ per set and total maximum of electrical power muti-terminal with wind turbines energy about 87MVA. The electrical energy form PMSG system supplies the VSC, which is controlled by two-level series connection bidirectional ac/dc converter for regulating the DC link voltage at $\pm 300 \mathrm{kVDC}$. The parameters for the tester experimental and simulation by MATLAB Simulink with two-level SPWM converter. The performance of proposed PQ-control with voltage and current command $(\alpha, \beta$-axis), the controller design the inner control loop in $\alpha$-axis and $\beta$ -axis control can be done independently. Tuning of PI controllers in the current loops approach is to use the axis decoupling by means of feed forward control loops must be turn, the PI controllers in the outer control loops must be tuned to achieve a reasonable crossover, by in case short duration time. The parameter form a table for setup for design and improvement voltage source converter for containing load rating of $300 \mathrm{MW}$ for interconnection between from Thailand (station1) to Malaysia (station2) station with control of an asynchronous back to back VSC-HVDC system.

Table 1. Main system parameters the tester experimental \& simulation

\begin{tabular}{|c|c|c|c|}
\hline \multirow{6}{*}{$\begin{array}{l}\text { Station } 1 \text { (Rectifier Side) Thailand } \\
\text { PMSG(Wind energy) }\end{array}$} & Parameter & Rated-Value & Rated-Value \\
\hline & Grid line Voltage & $230 \mathrm{kV}($ Base $)$ & 1.0 \\
\hline & Frequency & $50 \mathrm{~Hz}$ (Base) & 1.0 \\
\hline & Rated Power & 348MVA(Base) & 1.0 \\
\hline & SCC, Impedance TR (Z) & $11.20 \%$ & - \\
\hline & Phase Shift Transformer $(Y / \Delta / Y)$ & $3 \times 116 \mathrm{MVA} / 230 \mathrm{kV} / 122.24 \mathrm{kV} / 822 \mathrm{~A}$ & - \\
\hline $\begin{array}{l}\text { Wind farms } \\
\text { Multi-Terminal } \\
\text { PMSG (Wind Energy) }\end{array}$ & $\begin{array}{l}\text { Nominal power of each Wind } \\
\text { Rated Power PMSG (50kVA) }\end{array}$ & 87MVA & 0.25 \\
\hline \multirow{5}{*}{ Station 2 (Inverter Side) Malaysia } & Grid line Voltage & $275 \mathrm{kV}$ (Base) & 1.19 \\
\hline & Frequency & $50 \mathrm{~Hz}$ (Base) & 1.0 \\
\hline & Rated Power & 348MVA(Base) & 1.0 \\
\hline & SCC, Impedance TR (Z) & $11.20 \%$ & - \\
\hline & Phase Shift Transformer $(Y / \Delta / Y)$ & $3 \times 3116 \mathrm{MVA} / 230 \mathrm{kV} / 122.24 \mathrm{kV} / 822 \mathrm{~A}$ & - \\
\hline \multirow{5}{*}{$\begin{array}{l}\text { VSC Two-Level } \\
\text { SPWM Converter }\end{array}$} & Rated Power & 300MVA & 0.86 \\
\hline & Switching frequency & $10 \mathrm{kHz}$ & 200 \\
\hline & Power IGBT/Diode & $1200 \mathrm{~A} / 1200 \mathrm{~V}$ & - \\
\hline & $\begin{array}{l}\text { LC-Filter HVDC Voltage Output } \\
\text { Reactor \&Capacitor }\end{array}$ & $\begin{array}{l}\mathrm{L} 1, \mathrm{~L} 2=1 \mathrm{mH} \\
\mathrm{C} 1, \mathrm{C} 2=85 \mathrm{uF}\end{array}$ & - \\
\hline & HVDC Voltage Output & $\pm 300 \mathrm{kVDC}$ & 1.3 \\
\hline $\begin{array}{l}\text { Cable: } 2400 \mathrm{~mm}^{2} / 15 \\
63 \mathrm{~A} / 321.5 \mathrm{kV}\end{array}$ & $\begin{array}{l}110 \mathrm{~km} \times 2 \text { cable } \\
(\mathrm{R}=0.0139 \Omega / \mathrm{km})\end{array}$ & $\begin{array}{l}\mathrm{L}=0.159 \mathrm{mH} / \mathrm{km} \\
\mathrm{C}=23.1 \mathrm{uF} / \mathrm{km}\end{array}$ & - \\
\hline $\begin{array}{l}\text { Power Control } \\
\text { Active Power (P) }\end{array}$ & $\mathrm{Kp}(\mathrm{P}), \mathrm{Ki}(\mathrm{P})$ & 8,10 & \\
\hline $\begin{array}{l}\text { Power Control } \\
\text { Reactive Power (Q) }\end{array}$ & $\mathrm{Kp}(\mathrm{Q}), \mathrm{Ki}(\mathrm{Q})$ & 4,10 & - \\
\hline
\end{tabular}




\section{Results}

The consideration $\mathrm{AC}$ side perturbations, given the converter 1 at rectifier-side (station 1 ) and converter 2 at the inverter side (station 2) was the controller designs are identical. An asynchronous back-to-back HVDC link based on VSC converter rated at $348 \mathrm{kVA}( \pm 300 \mathrm{kVDC})$ employing two-level SPWM converter hardware prototype as shown in figure the PWM has been tested for amplitude with modulation index ( $\mathrm{ma}=0.5,0.8)$ with sine wave with multicarrier waves for three phase two level SPWM system. AC side perturbations, given the converter, the converter at rectifier-side (station 1.) was the controller designs are identical. An asynchronous HVDC link based on VSC converter rated (No.1-No.8) about 87MVA ( $\pm 300 \mathrm{kVDC})$ employing two-level SPWM series voltage connection as shown in figure 6. For system simulations, the wind turbines speed profile for No.1 (Example for simulation) of wind turbines, where the minimum and maximum values of wind velocity $(\mathrm{m} / \mathrm{s})$ per rotational speed $(\mathrm{rad} / \mathrm{s})$ are respectively to $8.5 \mathrm{~m} / \mathrm{s} \quad(19.5 \mathrm{rad} / \mathrm{s})$ and $12.5 \mathrm{~m} / \mathrm{s}$ $(43 \mathrm{rad} / \mathrm{s})$ with an average value of $10.5 \mathrm{~m} / \mathrm{s}(35 \mathrm{rad} / \mathrm{s})$. The Simulation results, illustrate in Figure 6. The PQ-controller results consist of PMSG rotational speed, voltages and currents, the active and reactive power, DC-bus (kVDC), $\mathrm{DC}$-power $(\mathrm{Pdc})$ and step response command active power $\left(\mathrm{P}^{*}\right)$, The control of DC-bus voltage is assured by regulation of the active and reactive power. The control strategy of PQ-control to the two-level SPWM converters topology technique can be used for the realization of HVDC system.

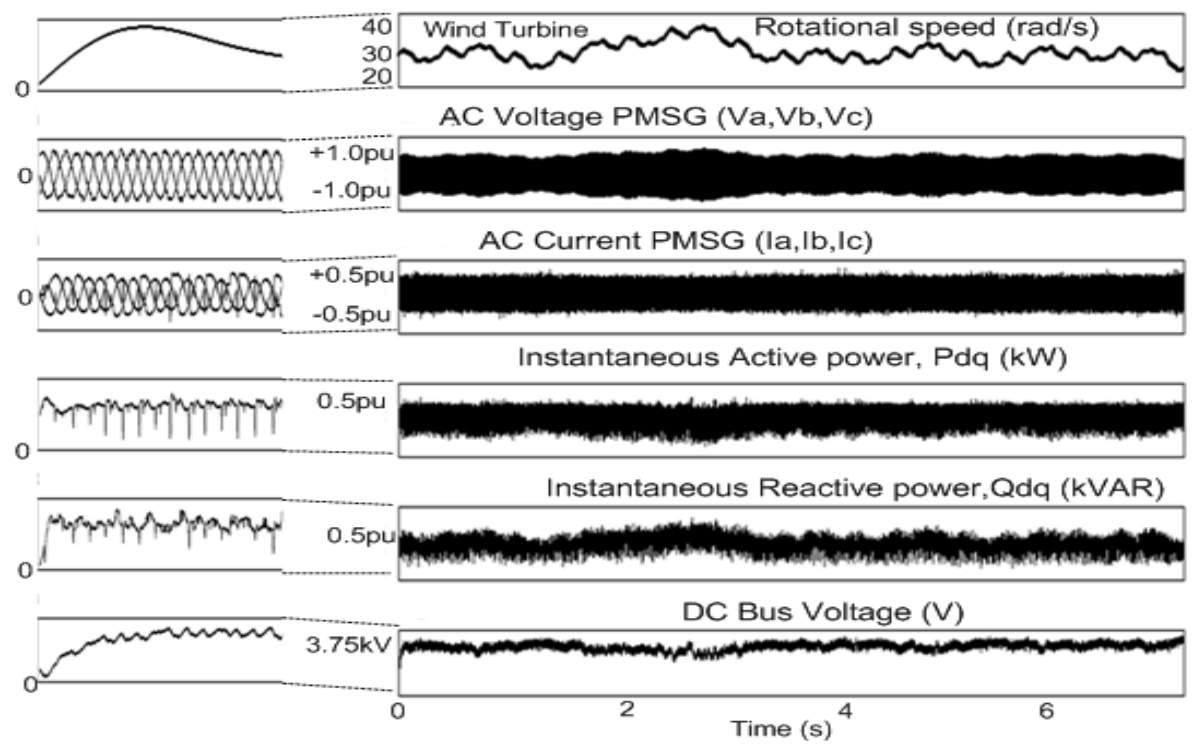

(a) Rotational speed

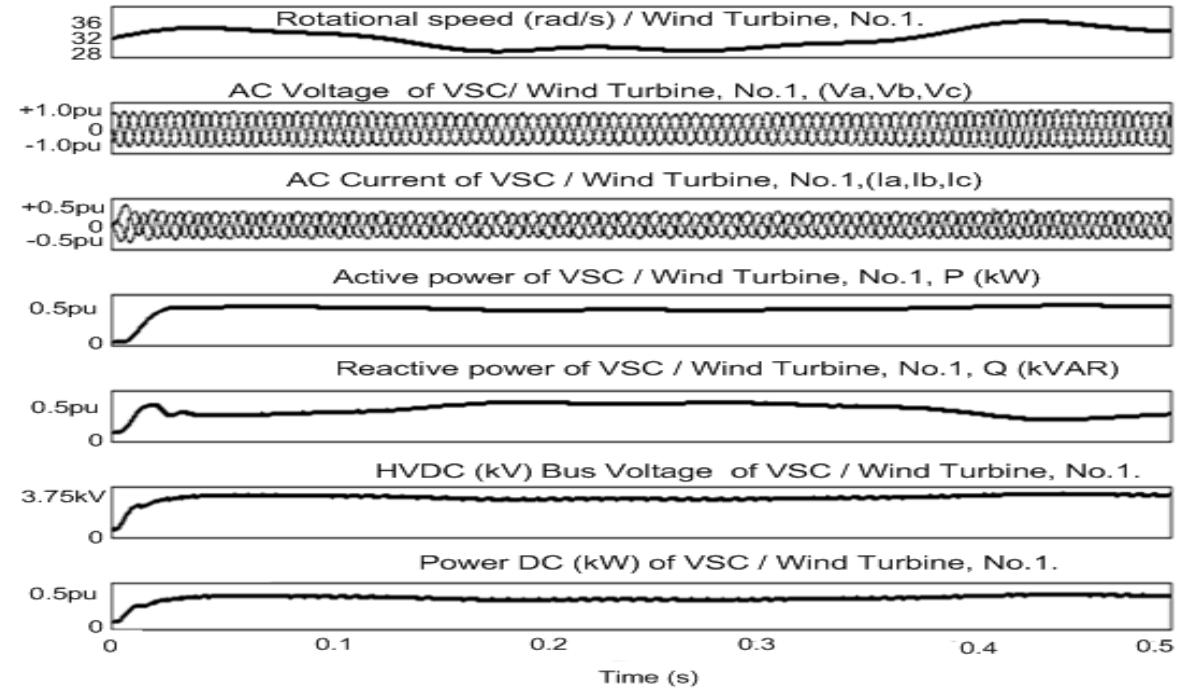

(b) $\mathrm{AC}$ side perturbations 
Rotational speed (rad/s)

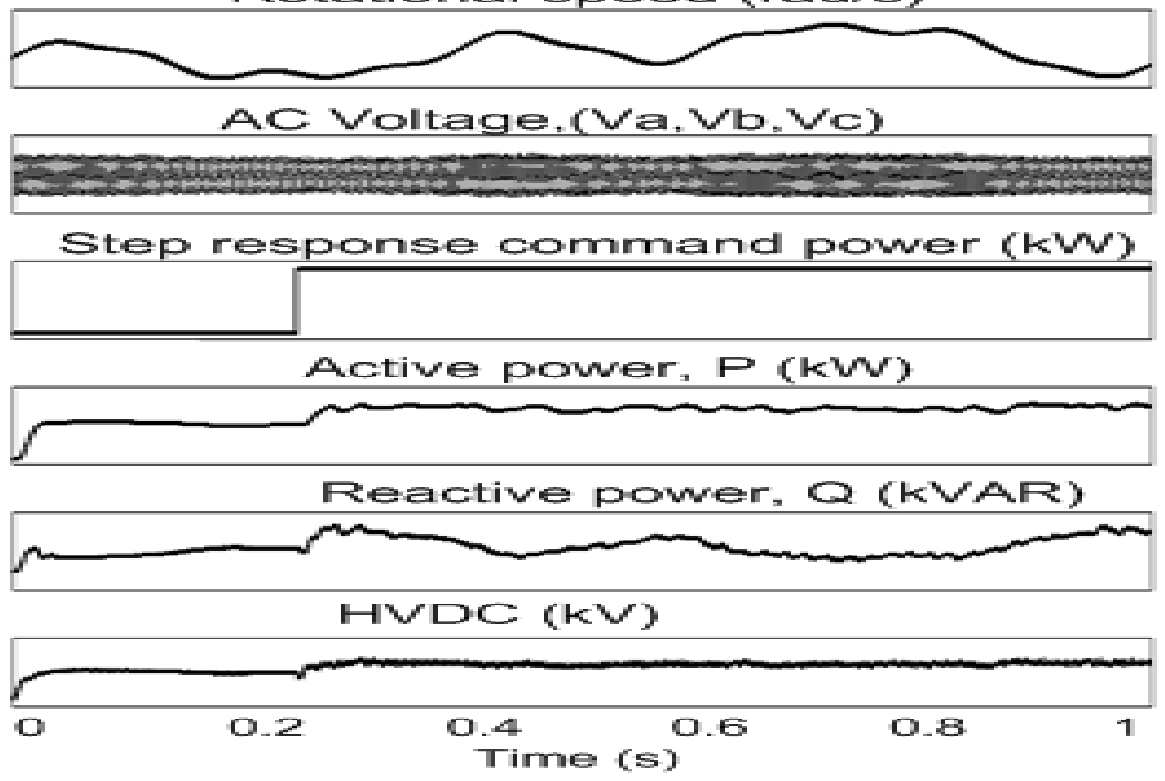

(c) Response command

Figure 6. Simulation results of wind turbines of PMSG No.1, respectively presented, (a) illustrate rotational speed (rad/s), outgoing from step-up transformer consist of $\mathrm{AC}$ voltage and current of PMSG ( $\mathrm{Va}, \mathrm{Vb}, \mathrm{Vc})$ and $(\mathrm{Ia}, \mathrm{Ib}, \mathrm{Ic})$, instantaneous active power (Pdq), instantaneous reactive power (Qdq), and DC-bus voltage (b) AC side perturbations with short duration time start of period $0.00-0.50$ second consist of rotational speed (rad/s), AC voltage and current of PMSG, active power (P), reactive power (Q), DC-bus voltage (kVDC) and DC-power bus (c) the step response command active power (P*) with short duration time starting of period 0.25 second up to $1 \mathrm{sec}$, respectively, the controller results waveform shown active power $(\mathrm{P})$, reactive power $(\mathrm{Q})$ and DC-bus voltage control loops.

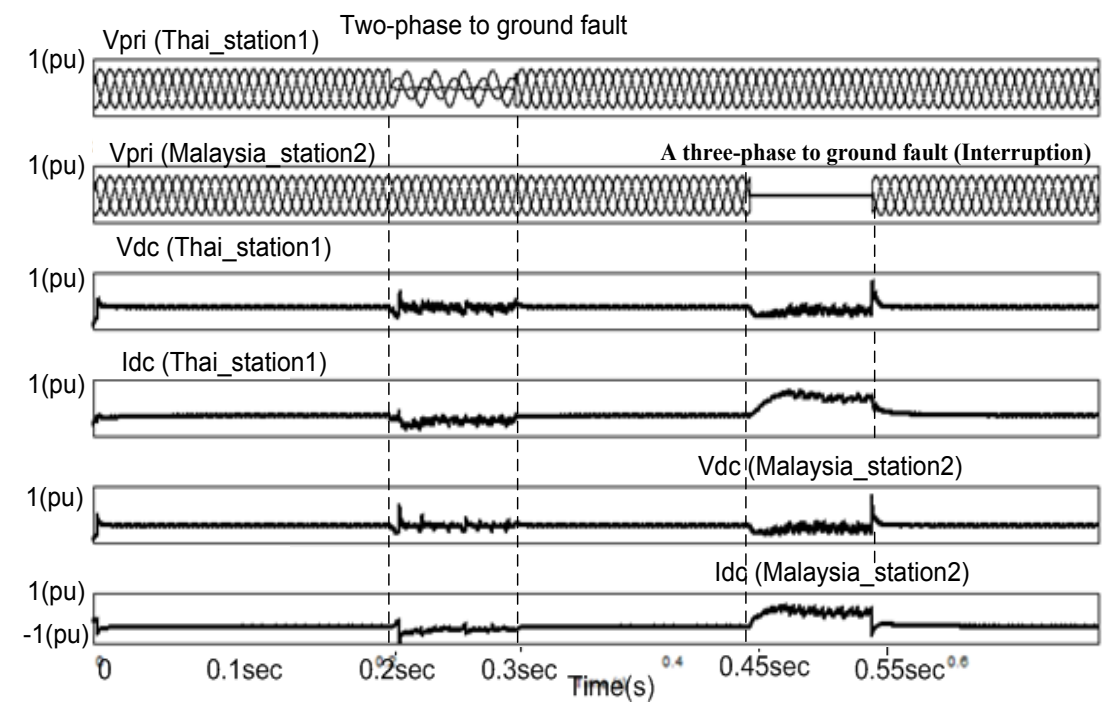

Figure 7. MATLAB Simulation waveforms of the studied system under test case a two-phase to ground fault with short duration time start of period 0.20 -0.30 second and at three-phase to ground fault (Interruption short duration time) at time, $\mathrm{t}=0.45-0.55$ second of AC side perturbations in station 1 (Thailand) and at station 2 (Malaysia) about real time value of AC voltage (Vpri), DC voltage and DC current.

AC side perturbation, A two phase to ground fault was first applied at $\mathrm{t}=0.2 \mathrm{sec}$. to $0.3 \mathrm{sec}$. at station 1 (Thailand) in order to investigate the behavior of VSC-HVDC during unbalance faults. A three-phase to ground fault (Interruption short duration time) is applied at station 2 (Malaysia) at time, $\mathrm{t}=0.45 \mathrm{sec}$. to $0.55 \mathrm{sec}$. is decreased to $0.0 \mathrm{pu}$ and recovers fast and successfully to $1.0 \mathrm{pu}$. As usually $\mathrm{t}<0.20 \mathrm{sec}$., the system operates in normal conditions and at $t>0.30$ sec., station 1 is de-energized to clear the fault and at $t>0.55 \mathrm{sec}$., station 2 is de-energized to clear the fault, as shown in Figure 7.

\section{Conclusions}

In this paper, we have presents a control strategy of PQ-control to the VSC-HVDC with the two-level SPWM converters topology technique for the realization of HVDC 
system. The VSC-HVDC and present development in Thailand, with control strategy based on onshore grid and offshore wind farms networks of Multi-Terminal VSC-HVDC. The power flows that can be controlled DC-bus voltage is assured by the regulation of the active power $(\mathrm{P})$ and reactive power $(\mathrm{Q})$. The power flows that the active power $(\mathrm{P})$ and reactive power $(\mathrm{Q})$ can controlled with no mutual interference. In addition, the performance of the VSC-HVDC from the simulation, it can fulfil fast and bi-directional power transfers was verified by fault condition (one to two phase to ground fault and three-phase to ground fault (Interruption short duration time), when the fault is cleared, normal operation is recovered fast. This study also provides guideline to further analyze. In the future, simulations should be carried out to identify the appropriateness of the controllers.

\section{REFERENCES}

[1] ABB Power Technologies. (2008). Powering Val hall platform with HVDC Light ${ }^{\circledR}$. Brochure.

[2] J.G. Slootweg, W.L. Kling. (2002). Modeling of Large Wind Farms in Power System Simulations. IEEE Power Engineering Society Summer Meeting. Chicago, USA.

[3] Z. Lubosny. (2003). Wind Turbine Operation in Electric Power Systems Advance Modeling. Springer-Verlag, Berlin.

[4] Lars Weimers. (2001). HVDC Light, the Transmission Technology of the future. Orkuping.

[5] Luxembourg, Belgium.(2006). European Technology Platform SmartGrids - Vision and Strategy for Europe's Electricity Networks of the Future.

[6] DENA Study Part 1.(2020). Energiewirtschaftliche Planung für die Netzintegration von Windenergie in Deutschland an Land und Offshore bis zum Jahr. Cologne, Germany.
[7] M.Luther,U.Radtke.(2001). Betrieb and Planung von Netzen mit hoher Windenergieeinspeisung. ETG Kongress, Nuremberg, Germany.

[8] N.G. Hingorani.(1993). Flexible AC Transmission. IEEE Spectrum, pp. 40-45.

[9] Mohamed Flitti et al. (2012). Control of back-to-back voltage source converter. Roum, Sci, Techn - Électrotechn, et Énerg, Bucarest, p. 259-268.

[10] A. Nabae, I. Takahashi, and H. Akagi.(1981). A New Neutral-point Clamped PWM inverter," IEEE Trans. Ind. Applicat, vol. IA-17, pp. 518-523.

[11] D.I. Stroe, A.I. Stan, I. Visa, I. Stroe. (2011). Modeling and Control of Variable Speed Wind Turbine Equipped with PMSG. 13th World d Congress in Mechanism and Machine Science, Guanajua'to, Mexico.

[12] M. Yi ng, G. Li, M. Zhou, and C. Zhao. (2007). Modeling of the wind turbine with a permanent magnet synchronous generator for integration. IEEE, SBN 1-4244-1298-6.

[13] Abdul Hamid Bhat and Pramod Agarwal. (2001). Improved power quality ac/dc National Institute of Technology Srinagar. Kashmir India.

[14] Samah Hammadi, Noureddine Hidouri, Lassâad Sbita. (2011). A DTC-PMSG-PMSM Drive Scheme for an Isolated Wind turbine water Pumping System. Vol. 1, No. 1, March.

[15] K. Ghdemsi, D. Aouzellzg.(2010). Improvement of the performances for wind energy conversion Systems. Electric Power and Energy Systems, vol. 32, pp. 936-945.

[16] L.M. Fernandez, C.A. Garcia, F. Jurado. (2010). Operating capability as a $\mathrm{PQ} / \mathrm{PV}$ node of a direct-drive wind turbine based on a permanent magnet synchronous generator. Renewable Energy, vol.35, pp.1308- 1318.

[17] Shuhui Li, Timothy A. Haskew, Ling Xu. (2010). Conventional and novel control designs for direct driven PMSG wind turbines. Electric Power Systems Research, vol.80, pp. 328-338. 